\title{
FITOTECNIA
}

\section{CRESCIMENTO E MICORRIZAÇÃO DE GENÓTIPOS DE MILHO EM CASA DE VEGETAÇÃO (1)}

\author{
DANIELA TIAGO DA SILVA CAMPOS (2); JOÃO ANTÔNIO DA COSTA ANDRADE ( $\left.{ }^{3}\right)$; \\ ANA MARIA RODRIGUES CASSIOLATO $\left(3^{*}\right)$
}

\begin{abstract}
RESUMO
O trabalho foi desenvolvido em casa de vegetação com o objetivo de comparar o crescimento e a micorrização por fungos micorrízicos arbusculares (FMA) em nove genótipos de milho, além de verificar o potencial de inóculo de FMA do solo. Coletado de uma área de cerrado sensu stricto ocupada por pastagem degradada, o solo foi adubado, misturado com areia de rio, fumigado e colocado em sacos plásticos $(3 \mathrm{~kg})$. Foram semeadas cinco sementes de cada genótipo de milho em 20 sacos, mas apenas 10 receberam cerca de 300 esporos de FMA, coletados do solo de pastagem. Cada saco constituiu-se em uma repetição, com apenas uma planta. As avaliações de altura e diâmetro do caule foram realizadas aos 15, 30, 45 e 60 dias após a emergência, além de massa seca do sistema radicular (MSR) e parte aérea (MSPA), colonização micorrízica (COL) e dependência micorrízica (DM). Concomitantemente, um segundo experimento foi realizado para avaliar o potencial de inóculo de FMA do solo de pastagem, o qual passou por uma diluição seriada de $90 \%, 80 \%, 70 \%, 60 \%, 50 \%, 40 \%, 30 \%, 20 \%$ e 10\%, incluindo apenas o solo não esterilizado $(100 \%)$ e somente solo esterilizado (0\%), em sacos plásticos, semeado o híbrido Tractor. Após 60 dias, as raízes foram colhidas para quantificar a colonização micorrízica. A inoculação de FMA acarretou incrementos na produção de matéria seca de forma diferenciada entre genótipos; com Condá, F0, D1 e F8 exibindo os maiores valores de MSPA, enquanto Tractor e D7 os menores valores de MSR. Os genótipos não responsivos ou pouco responsivos quanto à dependência micorrízica tiveram comportamento diferente quanto à COL, com Condá, Sol da Manhã, F0 e D1 proporcionando média de 60\%. Verificou-se que a área de pastagem, mesmo degradada, propiciou alto potencial de inóculo, revelado pela alta porcentagem de colonização das raízes por FMA.
\end{abstract}

Palavras chaves: Zea mays, espécies melhoradas, pastagem degradada, micorriza arbuscular, cerrado.

\section{ABSTRACT \\ GROWTH AND MYCORRHIZATION OF CORN GENOTYPES UNDER GREENHOUSE CONDITION}

This study was conducted in a greenhouse, with the objective of comparing the growth and mycorrhization of nine corn genotypes and the colonization by autoctonous arbuscular mycorrhizal fungi (AMF), in addition to the AMF soil inoculum potential. Soil was collected on a degraded pasture (originally a 'cerrado' area), fertilized, mixed with river sand, fumigated and placed in 3-kg plastic bags. Five seeds of each corn genotype were seeded in 20 bags, but only 10 received solution with 300 AMF spores ca., collected from the pasture soil. Each bag, containing one single plant, composed a replication. The plant height and stem diameter were evaluated in 15, 30, 45 and 60 days after seeded, plus dry matter weight of roots and canopy, colonization and mycorrhizal dependency. On the same period, the second experiment was prepared to evaluate the soil potential of FMA of pasture soil, with serial dilution of $90,80,70,60,50,40,30,20$ and $10 \%$, including only no sterilized soil (100\%) and only sterilized soil ( $0 \%$ ), on plastic bags, seeded with Tractor hybrid. After 60 days, roots were collected to quantify the COL. Inoculation of

(1) Recebido para publicação em 15 de dezembro de 2009 e aceito em 11 de março de 2010.

() Universidade Federal do Mato Grosso (UFMT). E-mail: camposdts@yahoo.com.br;

( $\left.{ }^{3}\right)$ UNESP-Universidade Estadual Paulista, Faculdade de Engenharia de Ilha Solteira, Avenida Brasil, 56, Caixa Postal 31, 15385-000 Ilha Solteira (SP). E-mail: jandrade@bio.feis.unesp.br, anamaria@bio.feis.unesp.br. (*) Autora correspondente. 


\begin{abstract}
AMF resulted in a differential increase of dry matter, with highest values of dry matter weight of canopy were found on the genotypes Condá, F0, D1 and F8 and lowest weight of roots for genotypes Tractor and D7. The genotypes showed no response or low response to the mycorrhyzae, and exhibited different response to colonization, with the averaging of $60 \%$ for Condá, Sol da Manhã, F0 and D1. The pasture area, even degraded, showed a high soil inoculum potential, presenting high root colonization percentage by FMA.
\end{abstract}

Key words: Zea mays, plant breeding, degraded pasture, cerrado vegetation (Brazilian savannah).

\section{INTRODUÇÃO}

$\mathrm{O}$ Brasil possui grande área de solos ácidos $\mathrm{e}$ distróficos, ocupada pelo bioma Cerrado, que totalizam 2,5 milhões de $\mathrm{km}^{2}$ (Silva et al., 2006). O processo de ocupação dessa área ocorreu de forma desordenada, sendo inicialmente utilizada para atividades extrativistas e produção pecuária extensiva, mas contava com pastagens nativas de baixa capacidade para a produção animal (DiAs e GrifFiTH, 1998). Estima-se que no Brasil mais de $60 \%$ das pastagens cultivadas seja do gênero Brachiaria, que se destaca pela relativa adaptação aos solos de baixa fertilidade (ZIMMER et al., 1994).

Ao contrário das pastagens produtivas e bem manejadas, as pastagens degradadas têm um impacto negativo sobre o meio ambiente em escala local e regional, com reflexos econômicos, como a perda da produtividade e da qualidade da forrageira, além das consequências nas características físicas, químicas e biológicas do solo. $\mathrm{O}$ manejo inadequado do solo tem causado compactação, redução dos microrganismos, perda da matéria orgânica e da fertilidade, aumentando, assim, os processos erosivos e, consequentemente, ocasionando uma redução na produtividade agrícola (Alvarenga e Souza, 1995).

Atualmente, as áreas de Cerrado vêm sendo ocupadas com extensas lavouras destinadas à produção de cereais, leguminosas e oleaginosas, sendo a região Centro-Oeste responsável por $32 \%$ desta produção. A produção de milho no Brasil é oriunda de regiões com algum tipo de estresse ambiental, como a região do Cerrado, onde mais de $70 \%$ da produção é realizada por pequenos e médios agricultores (IBGE, 2008).

Como forma de melhorar a produção de milho, tem-se os fungos micorrízicos arbusculares (FMA), que se associam simbioticamente com a maioria das plantas formando as estruturas denominadas micorrizas. A colonização das raízes pelos FMA resulta em um micélio abundante na rizosfera, o que ajuda a absorver maior quantidade de nutrientes do solo (MoreIRA e SiqueIRA, 2006).

Os benefícios advindos das associações micorrízicas são dependentes das interações entre o sistema radicular das plantas hospedeiras e dos fungos, em determinadas condições edafoclimáticas.
Desta forma, conhecer a densidade de propágulos infectivos, capacidade infectiva e efetividade dos FMA é fundamental para os estudos sobre ecologia e manejo destes fungos, bem como para auxiliar na introdução de espécies exóticas, quando for necessário (SiqueIra et al., 2002).

O potencial da cultura do milho associada aos FMA tem sido objeto de vários estudos, porém a influência do genótipo sobre essa associação tem sido pouco relatada. A maioria dos estudos envolvendo variações genéticas de plantas/fungos na colonização micorrízica emprega plantas adultas e as comparações são feitas na época de máxima infecção (dependendo da planta), não mencionando a história inicial da infecção (SMITH et al., 1992).

É necessário melhor conhecimento do potencial de utilização dos FMA no desenvolvimento e na nutrição mineral das plantas, bem como, acrescentar nos programas de melhoramento vegetal a seleção de plantas objetivando a maximização dos efeitos da micorriza na eficiência de utilização de nutrientes. Estes programas ajudariam a entender, em determinadas culturas, a variabilidade dos resultados observados quanto à colonização ou resposta à infecção. Esse fato se torna ainda mais importante quando o objetivo é a obtenção de cultivares rústicos para uma agricultura de baixa tecnologia. Assim, o presente trabalho foi desenvolvido em casa de vegetação, com o objetivo de comparar o crescimento e a micorrização por FMA em nove genótipos de milho, além de verificar o potencial de inóculo de FMA do solo.

\section{MATERIAL E MÉTODOS}

O experimento foi desenvolvido em casa de vegetação com solo coletado no município de Selvíria (MS). Originalmente, a área possuía como cobertura vegetal o cerrado sensu stricto, mas, no momento da coleta, estava ocupada com pastagem degradada, a qual não recebia calagem ou adubação há mais de quatro anos. O solo, um Latossolo Vermelho (EMBRAPA, 1999), foi coletado da camada arável $(0-20 \mathrm{~cm})$, peneirado (malha de $2 \mathrm{~mm}$ ) e homogeneizado. As características químicas foram determinadas segundo RaIJ e QuAGgio (1983) com os seguintes resultados: $\mathrm{pH}$ em $\mathrm{CaCl}_{2}=5,1 ; \mathrm{P}=5 \mathrm{mg} \mathrm{dm}^{-3} ; \mathrm{MO}=53 \mathrm{~g} \mathrm{dm}^{-3} ; \mathrm{K}=2,3$, 
$\mathrm{Ca}=27, \mathrm{Mg}=11, \mathrm{H}+\mathrm{Al}=28, \mathrm{Al}=0, \mathrm{SB}=39,8$ e $\mathrm{CTC}=$ $67,8 \mathrm{mmol}_{\mathrm{c}} \mathrm{dm}^{-3}$ e $\mathrm{V}=59 \%$.

A adubação do solo foi realizada aplicando-se 1/5 do fator de correção para o cultivo em vasos, segundo RAIJ et al. (1996) para a cultura do milho, utilizando-se uréia, superfosfato simples e cloreto de potássio nas seguintes quantidades: $10 \mathrm{~kg} \mathrm{ha}^{-1}$ de $\mathrm{N} ; 50 \mathrm{~kg} \mathrm{ha}^{-1}$ de $\mathrm{P}_{2} \mathrm{O}_{5}$ e $15 \mathrm{~kg} \mathrm{ha}^{-1}$ de $\mathrm{K}_{2} \mathrm{O}$. O substrato para as plantas consistiu de solo de pastagem degradado (corrigido e adubado), como mencionado e areia de rio lavada (4:1), fumigado com $263 \mathrm{~cm}^{3}$ de brometo de metila por $\mathrm{m}^{3}$ de substrato seco. Foram utilizados sacos plásticos (repetições) com $3 \mathrm{~kg}$ de substrato. Um dia antes da semeadura foram molhados e cada saco recebeu $100 \mathrm{~mL}$ de filtrado do solo peneirado e isento de propágulos de FMA, objetivando a equalização e reincorporação da microbiota do solo fumigado.

Os esporos de FMA foram obtidos de $100 \mathrm{~g}$ do mesmo solo utilizado para o preparo do substrato, pelo método de peneiramento por via úmida e decantação (GERDEMANn e Nicolson, 1963), seguido da centrifugação com sacarose (JENKINS, 1964).

Os nove genótipos de milho utilizados foram escolhidos por suas características quanto ao nível de melhoramento imposto para a sua obtenção e ao nível tecnológico exigido, como apresentado na tabela 1.

Foram semeadas cinco sementes de cada genótipo de milho em 20 sacos plásticos, mas apenas 10 receberam cerca de 300 esporos de FMA autóctones (espécies não previamente identificadas), coletados do solo de pastagem. Os sacos foram distribuídos aleatoriamente na casa de vegetação, onde permaneceram por 80 dias. O desbaste das plantas foi feito no $15^{\circ}$ dia da emergência, deixando uma planta por saco.

As medições de altura da planta foram realizadas, quinzenalmente, com auxílio de uma régua graduada, tomando-se a distância entre o solo e a folha mais nova e as medidas do diâmetro do caule $(\mathrm{cm})$, realizadas ao nível do solo, com auxílio de um paquímetro. Após 60 dias da emergência, a parte aérea foi coletada e determinou-se a massa da matéria seca da parte aérea (MSPA). O sistema radicular foi separado do solo, lavado e $1 \mathrm{~g}$ de raiz de cada repetição foi colhida aleatoriamente e armazenada em álcool 50\% para posterior análise. O restante foi seco e pesado para a determinação da massa seca (MSR).

Para a verificação da porcentagem de colonização por FMA, as raízes armazenadas foram clareadas em $\mathrm{KOH} 10 \%$, acidificadas com $\mathrm{HCl} 1 \%$, coloridas com azul de tripano $0,05 \%$ e preservadas em lactoglicerol (PHILLIPS e HAYMAN, 1970). A avaliação foi realizada pelo método de interseção em placa quadriculada, sob lupa binocular com aumento de 40 vezes, pelo método descrito por
Giovannetti e Mosse (1980). Os segmentos que tinham vesículas, arbúsculos ou hifas características, por vezes ligadas a esporos típicos, foram considerados como colonizados por FMA. O delineamento foi em esquema de parcelas subdivididas, onde o fator inoculação micorrízica foi a parcela e o fator genótipos a subparcela. Cada saco constituiu-se em uma repetição, com uma planta cada um, totalizando 10 repetições.

A dependência micorrízica foi calculada pela diferença entre a massa seca da parte aérea das plantas inoculadas e as não-inoculadas, dividida pelas nãoinoculadas, e expressa como porcentagem da biomassa

Tabela 1. Características dos genótipos de milho utilizados

\begin{tabular}{ll}
\hline Genótipos & Características \\
\hline Ag 9010 & Híbrido simples hiperprecoce, recomendado \\
& para condições de alta tecnologia (CRUZ e \\
& PEREIRA FILHO, 2009).
\end{tabular}

Tractor Híbrido duplo comercial da empresa Syngenta, de características rústicas, recomendado para média e baixa tecnologia (Cruz e Pereira Filho, 2009).

Sol da Manhã Variedade comercial da EMBRAPA, eficiente na utilização de nitrogênio e recomendada para pequenos agricultores e regiões de baixa altitude (Cruz e Pereira FILHO, 2009).

Piranão VD2 Variedade comercial obtida na ESALQ/USP, caracterizada como de porte baixo devido à homozigose para o gene "braquítico" e grão tipo dente (Мота, 2006).

Condá Variedade comercial obtida pela Empresa de Pesquisa Agropecuária de Santa Catarina (EMPASC), para atendimento a pequenos produtores (GANDIN et al., 1985).

FO

Composto flintisa original (variedade), obtido na FEIS/UNESP, a partir de germoplasma de grãos duros (МотA, 2006).

F 8 Composto flintisa (variedade não comercial), após oito ciclos de seleção sobre o flintisa original (F0), em solo de cerrado, em condições de baixa tecnologia, sendo sete ciclos para melhorar o rendimento e um ciclo para diminuir a altura da espiga (MотA, 2006).

D1 Composto dentado (variedade não comercial) com um ciclo de seleção sobre o Dentado original, em solo de cerrado, em condições de baixa tecnologia, para melhor rendimento (MотA, 2006).

D 7 Composto dentado (variedade) com sete ciclos de seleção sobre o Dentado original, em solo de cerrado, em condições de baixa tecnologia, sendo seis ciclos para melhorar rendimento e um para diminuir altura da espiga (МотА, 2006). 
seca de plantas inoculadas (Plenchette et al., 1983). Com base nas respostas das plantas inoculadas para produção de MSPA, os genótipos foram categorizados em: altamente responsivos (resposta acima de 1000\% sobre o controle), muito responsivos (resposta entre $500 \%$ e $999 \%$ ), responsivos (resposta entre $100 \%$ e $499 \%$ ), pouco responsivos (resposta entre $20 \%$ e 99\%), não responsivos (resposta entre 19\% e -19\%) e depressivos (resposta abaixo de -20\%).

No segundoensaio, para a avaliação do potencial de inóculo dos FMA, o substrato foi preparado como descrito anteriormente, sendo apenas metade esterilizada. Uma diluição foi preparada usando o solo esterilizado e o não-esterilizado, nas porcentagens de $90 \%, 80 \%, 70 \%, 60 \%, 50 \%, 40 \%, 30 \%, 20 \%$ e $10 \%$. O substrato não diluído $(0 \%)$ foi composto apenas de solo não esterilizado e o totalmente diluído (100\%), apenas de solo esterilizado. Estes foram colocados em sacos plásticos com capacidade para $3 \mathrm{~kg}$ de substrato. $\mathrm{O}$ delineamento foi o inteiramente casualizado, com seis repetições. Foi utilizado o híbrido duplo comercial Tractor (Tabela 1), sendo semeadas cinco sementes por saco. Após o desbaste, aos 15 dias após a emergência (DAE), foi deixada apenas uma planta por saco. Após 60 dias de crescimento, as raízes foram colhidas, lavadas e usadas para quantificar a colonização micorrízica, segundo metodologia descrita anteriormente.

Os resultados foram submetidos à análise de variância e teste de Tukey a 5\% de probabilidade utilizando-se o programa SANEST (ZONTA et al., 1984).

\section{RESULTADOS E DISCUSSÃO}

A altura das plantas dos diferentes genótipos, submetidos à inoculação (inoc) e sem inoculação (n-inoc) de FMA, revelou diferenças significativas apenas na avaliação realizada no $15^{\circ}$ dia após a emergência das plantas. Para diâmetro do colmo não foram observadas diferenças significativas (Tabela 2).

Entre as plantas que não receberam o inóculo de FMA, as do genótipo Tractor tinham maiores valores de crescimento, entretanto, quando na presença de FMA, houve efeito inverso, ou seja, esse genótipo exibiu o menor crescimento e, consequentemente, as menores alturas, demonstrando a influência negativa da inoculação. Já os genótipos Sol da Manhã, Ag 9010, D1, F8 e D7 responderam à micorrização, ou seja, aprendendo os maiores valores no tratamento com inoculação (Tabela 2).

Os genótipos Sol da Manhã, Ag 9010 e D1, quando não receberam os inóculos de FMA, tiveram os mais baixos desenvolvimentos, com alturas de 5,21, 5,81 e 5,09 cm respectivamente. Quando foram submetidos à inoculação, ficou evidente um acréscimo significativo no desenvolvimento das plantas (Tabela 2), possivelmente por meio do aumento da absorção de água e nutrientes.

De acordo com o apresentado na tabela 3, quando avaliada a MSR, todos os genótipos responderam positivamente à inoculação de FMA, ou seja, houve um aumento na produção de massa seca. Para a MSPA esta diferença não foi tão pronunciada, havendo apenas alguns genótipos com aumento no ganho da matéria seca advindo da inoculação com FMA, sendo eles Condá, F0, F8 e D1. Dentre os genótipos que receberam e os que não receberam o inóculo de FMA, também não foram observadas diferenças na produção de MSPA.

As populações de FMA têm sido suficientes para promover bom desenvolvimento das plantas. Os efeitos da inoculação com FMA, segundo SMITH e READ (1997), podem acarretar diferentes resultados nas plantas hospedeiras, desde pequeno a um ótimo desenvolvimento. A colonização micorrízica é uma característica que pode ser afetada por inúmeros fatores, como a espécie vegetal, a idade da planta, a densidade de raízes, dos propágulos de FMA no solo, a eficiência de colonização de FMA e o manejo do solo, dentre outros (AғEK et al., 1990). Como não foi realizada a identificação dos possíveis gêneros de FMA inoculados ao solo, os genótipos estudados podem ter propiciado baixa afinidade a eles, resultando em baixo desenvolvimento (Tabelas 2 e 3) .

As maiores produções de MSR, sem a inoculação com os FMA, foram dos genótipos D7, Tractor e F8, com um comportamento diferenciado em relação ao Condá, Ag9010 e F0. No tratamento com inoculação, o maior valor foi do genótipo D7, que diferiu apenas do Ag9010, com o menor valor (Tabela 3).

Verificou-se que os oito ciclos de seleção praticados no milho Flintisa (F0 e F8) foram responsáveis pelo aumento da MSR, de 3,84 g planta $^{-1}$ (F0) para 7,32 g planta ${ }^{-1}(\mathrm{~F} 8)$, nos tratamentos que não receberam o inóculo de FMA. Com a inoculação, esta diferença deixou de existir, sendo 10,5 g planta $^{-1}$ para F0 e 11, $87 \mathrm{~g}$ planta $^{-1}$ para F8. No entanto, tanto em F0 como em F8 ocorreram os maiores valores de MSR quando inoculados. O mesmo não ocorreu para os genótipos D1 e D7 (Tabela 3).

Resultados semelhantes aos observados neste trabalho foram relatados por McGoingLe et al. (1990) que, trabalhando com solo degradado, observaram aumentos na produção de MSPA de milho em solo degradado, em decorrência da inoculação com FMA. PACOVSKY (1989), no entanto, utilizando cerca de 100 a 120 esporos de Glomus etunicatum por kg de solo adubado com fósforo, 
Tabela 2. Altura e diâmetro de colmo de genótipos de milho, submetidos à inoculação de esporos de fungos micorrízicos arbusculares (inoc) e sem inoculação (n-inoc), avaliados aos 15, 30, 45 e 60 dias após a emergência (DAE). Média de 10 repetições

\begin{tabular}{|c|c|c|c|c|}
\hline \multirow{2}{*}{ Genótipos } & \multicolumn{2}{|c|}{ Altura } & \multicolumn{2}{|c|}{ Diâmetro } \\
\hline & n-inoc & inoc & n-inoc & inoc \\
\hline & & & 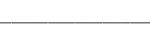 & 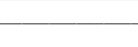 \\
\hline & & & & \\
\hline Tractor & 8,13 a $A$ & $5,28 \mathrm{~b}$ B & $0,6020 \mathrm{aA}$ & $0,9340 \mathrm{aA}$ \\
\hline Condá & $6,43 \mathrm{bcA}$ & $6,76 \mathrm{abA}$ & $0,5450 \mathrm{aA}$ & $0,5720 \mathrm{aA}$ \\
\hline Sol da Manhã & $5,21 \mathrm{c} \mathrm{B}$ & $6,17 \mathrm{abA}$ & $0,5510 \mathrm{aA}$ & $0,1163 \mathrm{aA}$ \\
\hline Piranão VD2 & $6,42 \mathrm{bcA}$ & $5,23 \mathrm{~b}$ B & $0,5540 \mathrm{aA}$ & $0,5310 \mathrm{aA}$ \\
\hline Ag 9010 & $5,81 \mathrm{c} \mathrm{B}$ & 6,98 a $\mathrm{A}$ & $0,5060 \mathrm{aA}$ & $0,5960 \mathrm{aA}$ \\
\hline F 0 & 7,56 abA & 7,31 a $\mathrm{A}$ & $0,6120 \mathrm{aA}$ & $0,6320 \mathrm{aA}$ \\
\hline D 1 & 5,09 c B & 7,00 a $\mathrm{A}$ & $0,5530 \mathrm{aA}$ & $0,6160 \mathrm{aA}$ \\
\hline F 8 & $6,22 \mathrm{bcB}$ & 7,39 a $\mathrm{A}$ & $0,5710 \mathrm{aA}$ & $0,6330 \mathrm{aA}$ \\
\hline D 7 & $6,22 \mathrm{bcB}$ & 7,39 a $\mathrm{A}$ & $0,5700 \mathrm{aA}$ & $0,6330 \mathrm{aA}$ \\
\hline Média & 6,34 & 6,69 & 0,5637 & 0,5848 \\
\hline \multirow[t]{2}{*}{$\mathrm{CV}(\%)$} & \multicolumn{2}{|c|}{2,49} & \multicolumn{2}{|c|}{0,21} \\
\hline & \multicolumn{4}{|c|}{30 DAE } \\
\hline Tractor & $16,09 \mathrm{aA}$ & $14,17 \mathrm{aA}$ & $1,0698 \mathrm{aA}$ & $1,1025 \mathrm{aA}$ \\
\hline Condá & $15,40 \mathrm{aA}$ & $15,80 \mathrm{aA}$ & $1,0360 \mathrm{aA}$ & $1,0425 \mathrm{aA}$ \\
\hline Sol da Manhã & $14,68 \mathrm{aA}$ & $14,49 \mathrm{aA}$ & $1,1140 \mathrm{aA}$ & $1,1112 \mathrm{aA}$ \\
\hline Piranão VD2 & $14,64 \mathrm{aA}$ & $12,57 \mathrm{aA}$ & $1,0310 \mathrm{aA}$ & $0,9670 \mathrm{aA}$ \\
\hline Ag 9010 & $14,45 \mathrm{aA}$ & $15,32 \mathrm{aA}$ & $1,0050 \mathrm{aA}$ & $0,9980 \mathrm{aA}$ \\
\hline F 0 & $15,46 \mathrm{aA}$ & $14,42 \mathrm{aA}$ & $1,0660 \mathrm{aA}$ & $1,0950 \mathrm{aA}$ \\
\hline D 1 & $13,70 \mathrm{aA}$ & $14,45 \mathrm{aA}$ & $1,0570 \mathrm{aA}$ & $1,0805 \mathrm{aA}$ \\
\hline F 8 & $14,73 \mathrm{aA}$ & $14,44 \mathrm{aA}$ & $1,1045 \mathrm{aA}$ & $1,1090 \mathrm{aA}$ \\
\hline D 7 & $15,51 \mathrm{aA}$ & $15,48 \mathrm{aA}$ & $1,0785 \mathrm{aA}$ & $1,0640 \mathrm{aA}$ \\
\hline Média & 14,9633 & 14,5744 & 1,0624 & 1,0633 \\
\hline \multirow[t]{2}{*}{ CV (\%) } & \multicolumn{2}{|c|}{2,30} & \multicolumn{2}{|c|}{0,31} \\
\hline & \multicolumn{4}{|c|}{$45 \mathrm{DAE}$} \\
\hline Tractor & $25,85 \mathrm{aA}$ & $24,72 \mathrm{aA}$ & $1,4725 \mathrm{aA}$ & $1,3890 \mathrm{aA}$ \\
\hline Condá & $25,66 \mathrm{aA}$ & $27,62 \mathrm{aA}$ & $1,2610 \mathrm{aA}$ & $1,1985 \mathrm{aA}$ \\
\hline Sol da Manhã & $23,37 \mathrm{aA}$ & $23,20 \mathrm{aA}$ & $1,2490 \mathrm{aA}$ & $1,1930 \mathrm{aA}$ \\
\hline Piranão VD2 & $18,78 \mathrm{aA}$ & $19,27 \mathrm{aA}$ & $1,2915 \mathrm{aA}$ & $1,4345 \mathrm{aA}$ \\
\hline Ag 9010 & $24,27 \mathrm{aA}$ & $23,63 \mathrm{aA}$ & $1,1565 \mathrm{aA}$ & $1,1675 \mathrm{aA}$ \\
\hline F 0 & $24,48 \mathrm{aA}$ & $24,66 \mathrm{aA}$ & $1,1725 \mathrm{aA}$ & $1,2300 \mathrm{aA}$ \\
\hline D 1 & $22,28 \mathrm{aA}$ & $23,85 \mathrm{aA}$ & $1,1665 \mathrm{aA}$ & $1,2700 \mathrm{aA}$ \\
\hline F 8 & $21,51 \mathrm{aA}$ & $22,52 \mathrm{aA}$ & $1,2770 \mathrm{aA}$ & $1,2615 \mathrm{aA}$ \\
\hline D 7 & $22,55 \mathrm{aA}$ & $24,96 \mathrm{aA}$ & $1,2305 \mathrm{aA}$ & $1,2265 \mathrm{aA}$ \\
\hline Média & 23,1955 & 23,8289 & 1,2530 & 1,2634 \\
\hline \multirow[t]{2}{*}{$\mathrm{CV}(\%)$} & \multicolumn{2}{|c|}{3,51} & \multicolumn{2}{|c|}{0,55} \\
\hline & \multicolumn{4}{|c|}{$60 \mathrm{DAE}$} \\
\hline Tractor & $55,19 \mathrm{aA}$ & $56,22 \mathrm{aA}$ & $1,3845 \mathrm{aA}$ & $1,4105 \mathrm{aA}$ \\
\hline Condá & $54,64 \mathrm{aA}$ & $58,36 \mathrm{aA}$ & $1,2685 \mathrm{aA}$ & $1,2295 \mathrm{aA}$ \\
\hline Sol da Manhã & $56,28 \mathrm{aA}$ & $61,50 \mathrm{aA}$ & $1,2695 \mathrm{aA}$ & $1,1810 \mathrm{aA}$ \\
\hline Piranão VD2 & $33,41 \mathrm{aA}$ & $28,78 \mathrm{aA}$ & $1,4535 \mathrm{aA}$ & $1,5835 \mathrm{aA}$ \\
\hline Ag 9010 & $71,30 \mathrm{aA}$ & $75,52 \mathrm{aA}$ & $1,1055 \mathrm{aA}$ & $1,1175 \mathrm{aA}$ \\
\hline F 0 & $55,68 \mathrm{aA}$ & $57,22 \mathrm{aA}$ & $1,1780 \mathrm{aA}$ & $1,2350 \mathrm{aA}$ \\
\hline D 1 & $48,91 \mathrm{aA}$ & $50,07 \mathrm{aA}$ & $1,2233 \mathrm{aA}$ & $1,2630 \mathrm{aA}$ \\
\hline F 8 & $42,03 \mathrm{aA}$ & $46,31 \mathrm{aA}$ & $1,3205 \mathrm{aA}$ & $1,2905 \mathrm{aA}$ \\
\hline D 7 & $47,82 \mathrm{aA}$ & $56,51 \mathrm{aA}$ & $1,2215 \mathrm{aA}$ & $1,2225 \mathrm{aA}$ \\
\hline Média & 51,6990 & 54,5032 & 1,2693 & 1,2814 \\
\hline $\mathrm{CV}(\%)$ & \multicolumn{2}{|c|}{3,84} & \multicolumn{2}{|c|}{0,56} \\
\hline
\end{tabular}

Médias seguidas pela mesma letra (minúscula na coluna e maiúscula na linha), dentro de cada variável, não diferem entre si pelo teste de Tukey a 5\% de significância. 
Tabela 3. Produção de matéria seca do sistema radicular (MSR) e da parte aérea (MSPA) de genótipos de milho submetidos à inoculação (inoc) e sem inoculação (n-inoc) de fungos micorrízicos arbusculares, aos 60 dias após a emergência. Média de 10 repetições

\begin{tabular}{|c|c|c|c|c|}
\hline \multirow{2}{*}{ Genótipos } & \multicolumn{2}{|c|}{ MSR } & \multicolumn{2}{|c|}{ MSPA } \\
\hline & n-inoc & inoc & n-inoc & inoc \\
\hline Tractor & 7,69 a $\mathrm{B}$ & 9,50 abcA & $23,79 \mathrm{aA}$ & $24,79 \mathrm{aA}$ \\
\hline Condá & $4,19 \mathrm{~b}$ B & $9,20 \mathrm{abcA}$ & $19,67 \mathrm{aB}$ & $21,84 \mathrm{aA}$ \\
\hline Sol da Manhã & $5,54 \mathrm{abB}$ & $9,78 \mathrm{abcA}$ & $23,23 \mathrm{aA}$ & $22,32 \mathrm{aA}$ \\
\hline Piranão VD2 & $5,11 \mathrm{abB}$ & 10,99 abcA & $21,75 \mathrm{aA}$ & $22,64 \mathrm{aA}$ \\
\hline Ag 9010 & $3,90 \mathrm{~b} B$ & $7,46 \mathrm{c} \quad \mathrm{A}$ & $24,56 \mathrm{aA}$ & $22,86 \mathrm{aA}$ \\
\hline F 0 & $3,84 \mathrm{~b}$ B & $10,51 \mathrm{abcA}$ & $20,67 \mathrm{aB}$ & 23,35 aA \\
\hline D 1 & $5,64 \mathrm{abB}$ & $12,92 \mathrm{ab} \mathrm{A}$ & $18,95 \mathrm{aB}$ & $23,08 \mathrm{aA}$ \\
\hline F 8 & 7,32 a $\mathrm{B}$ & $11,87 \mathrm{ab} A$ & $21,02 \mathrm{aB}$ & $24,30 \mathrm{aA}$ \\
\hline D 7 & 8,05 a $\mathrm{B}$ & 13,09 a A & $20,22 \mathrm{aA}$ & $22,18 \mathrm{aA}$ \\
\hline Média & 5,69 & 10,59 & 21,54 & 23,04 \\
\hline CV $(\%)$ & & & & \\
\hline
\end{tabular}

Médias seguidas pela mesma letra (minúscula na coluna e maiúscula na linha), dentro de cada variável, não diferem entre si pelo Teste de Tukey a 5\% de significância.

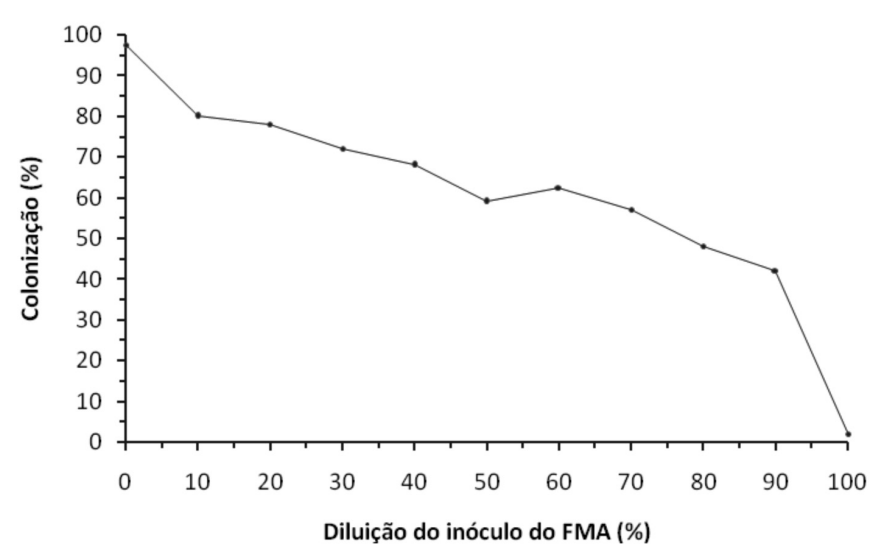

Figura 1. Colonização micorrízica de raízes de milho híbrido Tractor, em diferentes diluições do inóculo de fungos micorrízicos arbusculares, aos 60 dias após a emergência. Média de seis repetições.

não verificaram diferenças significativas na produção de matéria seca em plantas de milho.

Nos genótipos, observou-se comportamento não responsivo à dependência micorrízica, exceto o D1, que foi pouco responsivo $(21,79 \%)$. No entanto, a colonização micorrízica foi, em média, de 57,77\% dentre os genótipos que receberam a inoculação com FMA, sendo as maiores taxas observadas para Sol da Manhã, DI, Condá, F0, Piranão VD2 e F8. As menores porcentagens de colonização observadas foram de 35,7\% para o genótipo D7, que na produção de MSR exibiu elevado ganho na produção, evidenciando que, apesar da baixa porcentagem de colonização, os FMA que se associaram às raízes, parecem ter sido eficientes na simbiose e favorecendo o desenvolvimento das plantas.
Os valores médios de porcentagem de colonização micorrízica constatados neste estudo estão próximos aos relatados por Siqueira et al. (1989), Maia e Trufem (1990) e CARRENHO et al. (2001). É notório que as espécies de gramíneas, como milho, sorgo, milheto e Brachiaria decumbens favoreçam a esporulação de FMA, sendo muito utilizadas para a multiplicação dos esporos, visto que à estrutura do sistema radicular, com várias raízes finas, facilita ainda mais a multiplicação de propágulos infectivos (ReIs et al., 1991).

O resultado do potencial de inóculo do solo revelou que na área estudada havia propágulos de FMA com alta capacidade infectiva. A porcentagem de colonização das raízes no solo que não foi diluído foi alta, reduzindo gradativamente com o aumento na diluição (Figura 1). A porcentagem de colonização das raízes não deve ser interpretada como a taxa de atividade do fungo e, sim, como a capacidade que eles possuem em associarem às plantas (SIEVERDING, 1991).

O número de propágulos fúngicos utilizado neste ensaio, cerca de 300 esporos de FMA é uma quantidade considerada razoável para as condições experimentais empregando inóculos de FMA purificados em condições naturais. WEBER et al. (2004), estudando o efeito de inoculação de FMA (entre 100 e 200 esporos aplicados por vasos plásticos de 1,5 L) em plântulas de cajueiroanão-precoce, relataram que a associação simbiótica foi vantajosa no desenvolvimento das mudas do cajueiro, aos quatro meses da semeadura.

Entretanto, em relatos verifica-se que os fragmentos de raízes colonizadas e o micélio presente no solo podem ser tão ou mais infectivos do que os esporos, firmando assim, sua importância na ecologia dos FMA (SMITH e 
READ, 1997). Para o potencial de inóculo, a presença de segmentos de raízes infectadas, além dos esporos, pode ter influenciado nos resultados deste estudo.

Relacionando a porcentagem de colonização dos genótipos de milho com o potencial micorrízico do solo, foi possível verificar que a porcentagem de colonização média de $57,77 \%$ foi comparável com o resultado anotado para a diluição de $50 \%$ do teste de potencial de inóculo do solo (Figura 1). Desta forma, a capacidade infectiva dos esporos submetidos à inoculação é comparável ao total de propágulos presentes no solo e infectando as raízes para a diluição de $50 \%$.

Os mecanismos que regulam o desenvolvimento e a atividade dos FMA, ainda não foram completamente elucidados, mas sabe-se que há alterações bioquímicas tanto no fungo como no hospedeiro e estas alterações ocorrem em decorrência do processo de colonização (SiqueIra et al., 2002). Assim, as diferenças nas taxas de colonização constatadas nas raízes dos genótipos, avaliadas neste estudo, podem ser decorrentes da produção de substâncias inibitórias em resposta à infecção, como os compostos fenólicos e fitoalexinas, ou de substâncias promotoras de crescimento, como os carboidratos.

O incremento e a seleção de genótipos com rápida e alta capacidade de colonização, com efeito benéfico para as plantas, podem ser um dos fatores a serem incorporados aos programas de melhoramento genético no futuro. Neste ensaio, as raízes do tratamento-controle, com solo não esterilizado e sem diluição, exibiram $90 \%$ de colonização micorrízica, enquanto na maior diluição $(90 \%)$, a porcentagem de colonização foi cerca de $40 \%$, permanecendo alta.

O solo utilizado, oriundo de uma pastagem degradada, apesar de não receber calagem há quatro anos, revelou conter elevada quantidade de propágulos viáveis de FMA. Estes resultados mostram que, apesar das perturbações ocorridas área nesta ao longo de muitos anos, os FMA são resistentes e com capacidade de multiplicação, mantendo alto potencial de inóculo composto por propágulos bem infectivos.

Devido à natureza ubíqua, à ausência de especificidade hospedeira e à suscetibilidade generalizada das plantas à micorrização, os FMA proporcionam enorme potencial biotecnológico; o conhecimento da densidade de propágulos infectivos e da capacidade infectiva é fundamental para o desenvolvimento de estudos sobre ecologia e manejo destes fungos auxiliando na introdução de fungos exóticos ao sistema (SIQUeIRA et al., 2002).

O potencial de inóculo dos FMA nos solos brasileiros tem sido investigado, porém faltam subsídios para melhor entendimento da influência de FMA indígenas em seus hospedeiros, em condições naturais (Espíndola et al., 1998).

Neste trabalho foi observado que a inoculação das plantas com FMA acarretou incremento na produção de matéria seca de forma diferenciada entre os genótipos, com o Condá, F0, D1 e F8 exibindo os maiores valores de MSPA, enquanto Tractor e D7 os menores valores de MSR. Os genótipos tiveram desenvolvimento diferente quanto à colonização micorrízica, e em Condá, Sol da Manhã, F0 e D1 a colonização foi de $60 \%$, em média, nos tratamentos que receberam inóculo. Todavia, pode-se afirmar que todos os genótipos foram responsivos quanto à dependência micorrízica e o solo da área de pastagem, apesar de degradado, proporcionou alto potencial de inóculo.

\section{CONCLUSÕES}

1. A inoculação de FMA acarreta incrementos na produção de matéria seca, da parte aérea e do sistema radicular, de forma diferenciada entre genótipos de milho.

2. Nos genótipos não responsivos ou pouco responsivos à micorrizição, ocorre comportamento diferente quanto à colonização.

3. A área de pastagem, mesmo degradada, proporciona alto potencial de inóculo de FMA.

\section{REFERÊNCIAS}

AFEK, U.; RINALDELLI, E.; MENGE, J.A.; JOHNSON, E.L.V.; POND, E. Mycorrhizal inoculum colonization of cotton, onion and pepper seedlings. Journal of American Society of Horticultural Science, v.115, p.938-942, 1990.

ALVARENGA, M.I.N.; Souza, J.A. Atributos do solo e o impacto ambiental. Lavras: ESL/FAEPE, 1995. 140p. (Monografia - Curso de especialização)

CARRENHO, R.;SILVA, E.S.; TRUFEM, S.F.B.;BONONI, V.L.R. Successive cultivation of maize and agricultural practices on root colonization, number of spores and species of arbuscular mycorrhizal fungi. Brazilian Journal of Microbiology, v.32, p.262-270, 2001.

CRUZ, J.C.; PEREIRA FILHO, I.A. Milho cultivares para 2009/2010. Disponível em: http: / / www.cnpms.embrapa.br/ milho/cultivares/index.php. Acesso em 27/11/2009.

DIAS, L.E.; GRIFFITH, J.J. Conceituação e caracterização de áreas degradadas. In: DIAS, L.E.; MELLO, J.W.V. (Eds.) Recuperação de Áreas Degradadas. Viçosa: UFV/Sociedade Brasileira de Recuperação de Áreas Degradadas, 1998. p.1-9.

EMPRESA BRASILEIRA DE PESQUISA AGROPECUÁRIA EMBRAPA. Sistema brasileiro de classificação de solos. Rio de Janeiro: EMBRAPA/CNPSO, 1999. 412p. 
ESPÍNDOLA, J.A.A.; ALMEIDA, D.L.; GUERRA, J.G.M.; SILVA, E.M.R.; SOUZA, F.A. Influência da adubação verde na colonização micorrízica e na produção de batata-doce. Pesquisa Agropecuária Brasileira, v.33, p.339-47, 1998.

GANDIN, C.L.; DIAZ, M.E.G.; CANTON, T.; ZANINI NETO, J.A. Características agronômicas das variedades de milho Empasc 151-Conda e Empasc 152-Oeste. Pesquisa Agropecuária Brasileira, v.20, p.793-798, 1985.

GERDEMANN, J.W.; NICOLSON, T.H. Spores of mycorrhyzal Endogone species extracted from soil by wet sieving and decanting. Transaction of the British Mycology Society, v.46, p.235-44, 1963.

GIOVANNETTI, M.; MOSSE, B. An evaluation of techniques for measuring vesicular arbuscular mycorrhizal infection in roots. New Phytologist, v.84, p.489-500, 1980.

INSTITUTO BRASILEIRO DE GEOGRAFIA E ESTATÍSTICA (IBGE). Levantamento Sistemático da Produção Agrícola. Acesso em: 25 de maio de 2008. Disponível em: http:/ / www. ibge.gov.br/home / estatistica/indicadores / agropecuaria/ lspa/1spa_200804comentarios.pdf

JENKINS, W.R. A rapid centrifugal-flotation technique for separating nematodes from soil. Plant and Soil, v.73, p.288300, 1964.

MAIA, L.C.; TRUFEM, S.F.B. Fungos micorrízicos vesículoarbusculares em solos cultivados no Estado de Pernambuco, Brasil. Revista Brasileira de Botânica, v.13, p.89-96, 1990.

McGOINGLE, T.P.; EVANS, D.G.; MILLER, M.H. Effect of degree of soil disturbance on mycorrhizal colonization and phosphorus absorption by maize in growth chamber and field experiments. New Phytologist, v.116, p.629-36, 1990.

MOREIRA, F.M.S.; SIQUEIRA, J.O. Microbiologia e Bioquímica do Solo. 2.ed. Lavras: UFLA, 2006. p.543-662.

MOTA, J.A. Doze ciclos de seleção no Composto Flintisa de milho, em condição de baixa tecnologia. 2006. 39f. Trabalho de Conclusão de Curso (Graduação em Agronomia). Universidade Estadual Paulista Júlio de Mesquita Filho, Ilha Solteira, 2006.

PACOVSKY, R.S. Metabolic difference in Zea-GlomusAzospirillum symbioses. Soil Biology and Biochemistry, v.21, p.953-960, 1989.

PHILLIPS, J.M.; HAYMAN, D.S. Improved procedures for clearing roots and staining parasitic and vesicular-arbuscular mycorrhizal fungi for rapid assessment of infection. Transaction of the British Mycology Society, v.55, p.158-61, 1970.

PLENCHETTE, C.; FORTIN, J.A.; FURLAN, V. Growth response of several plants species to mycorrhiza in a soil of moderate P fertility. I. Mycorrhizal dependency under field conditions. Plant and Soil, v.70, p.191-209, 1983.

RAIJ, B.V.; QUAGGIO, J.A. Métodos de análise de solos para fins de fertilidade. Campinas: Instituto Agronômico, 1983. 31p. (Boletim Técnico, 81)

RAIJ, B.; CANTARELlA, H.; CAMARGO, C.E.O. Cereais. In: RAIJ, B.; CANTARELLA, H; QUAGGIO, J.A.; FURLAN, A.M.C. (Ed.) Recomendações para adubação e calagem no Estado de São Paulo. 2.ed. Campinas: Instituto Agronômico, 1996. 285p. (Boletim Técnico, 100)

REIS, M.A.; ZAMBOLIM, L.; NASCIMENTO, J.R. Potencial de utilização de gramíneas para multiplicação de inóculo de fungos micorrízicos vesículo-arbuscular Glomus etunicatum. Fitopatologia Brasileira, v.16, p.164-170, 1991.

SIEVERDING, E. Ecology of VAM fungi in tropical agrosystems. Agriculture, Ecosystems and Environment, v.29, p.369-90, 1991.

SILVA, J.F.; FARIÑAS, M.R.; FELFILI, J.M.; KLI, C.A. Spatial heterogeneity, land use and conservation in the cerrado region of Brazil. Journal of Biogeography, v.33, p.536-548, 2006.

SIQUEIRA, J.O.; COLOZZI-FILHO, A.; OLIVEIRA, E. Ocorrência de micorrizas vesículo-arbusculares em agro e ecossistemas de Minas Gerais. Pesquisa Agropecuária Brasileira, v.24, p.1499-1506, 1989.

SIQUEIRA, J.O.; LAMBAIS, M.R.; STÜMER, S.L. Fungos micorrízicos arbusculares. Biotecnologia Ciência e Desenvolvimento, n.25, p.12-21, 2002.

SMITH, S.E.; READ, D.J. Mycorrhizal symbiosis. San Diego, California: Academic Press, 1997. 604p.

SMITH, S.E.; ROBSON, A.D.; ABBOTT, L.K. The involvement of mycorrhizas in assessment of genetically dependent efficiency of nutrient uptake and use. Plant and Soil, v.146, p.169-79, 1992.

WEBER, O.B.; SOUZA, C.C.; GONDIN, D.M.F.; OLIVEIRA, F.N.S.; CRISÓSTOMO, L.A.; CAPRONI, A.L.; SAGGIN JÚNIOR, O. Inoculação de fungos micorrízicos arbusculares e adubação fosfatada em mudas de cajueiro-anão-precoce. Pesquisa Agropecuária Brasileira, v.39, p.477-483, 2004.

ZIMMER, A.H.; MACEDO, M.C.M.; BARCELLOS, A.O.; KICHEL, A.N. Estabelecimento e recuperação de pastagens de Brachiaria. In: PEIXOTO, A.M.; MOURA, J.C.; FARIA, V.P. (Ed.). SIMPÓSIO SOBRE MANEJO DA PASTAGEM, 11. 1994, Piracicaba. Anais... Piracicaba: FEALQ, 1994. p.153-208.

ZONTA, E.P.; MACHADO, A.A.; SILVEIRA JUNIOR., P. Sistemas de análise estatística para microcomputadores (SANEST). Pelotas: Universidade Federal de Pelotas, 1984. $151 \mathrm{p}$. 